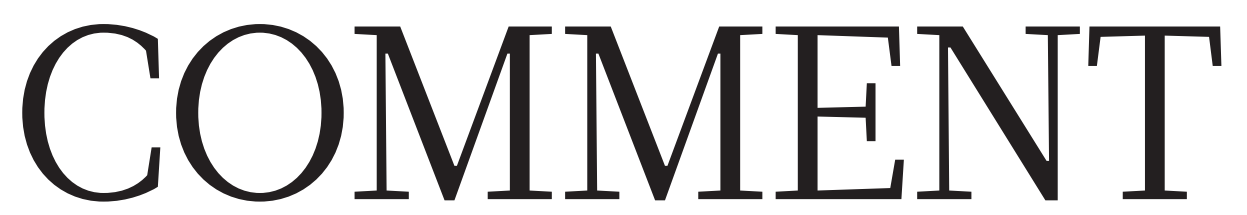

GOVERNANCE Sand is running out - rampant illegal mining must stop p.29
ENGAGEMENT Biography of Jacob Bronowski, giant of science TV, pulls its punches p.32
CONSERVATION Wild bees hold clues to saving hives from collapse p.34
SUSTAINABILITY Pity cetaceans and pinnipeds, the ocean is getting ever noisier $\mathbf{p . 3 6}$

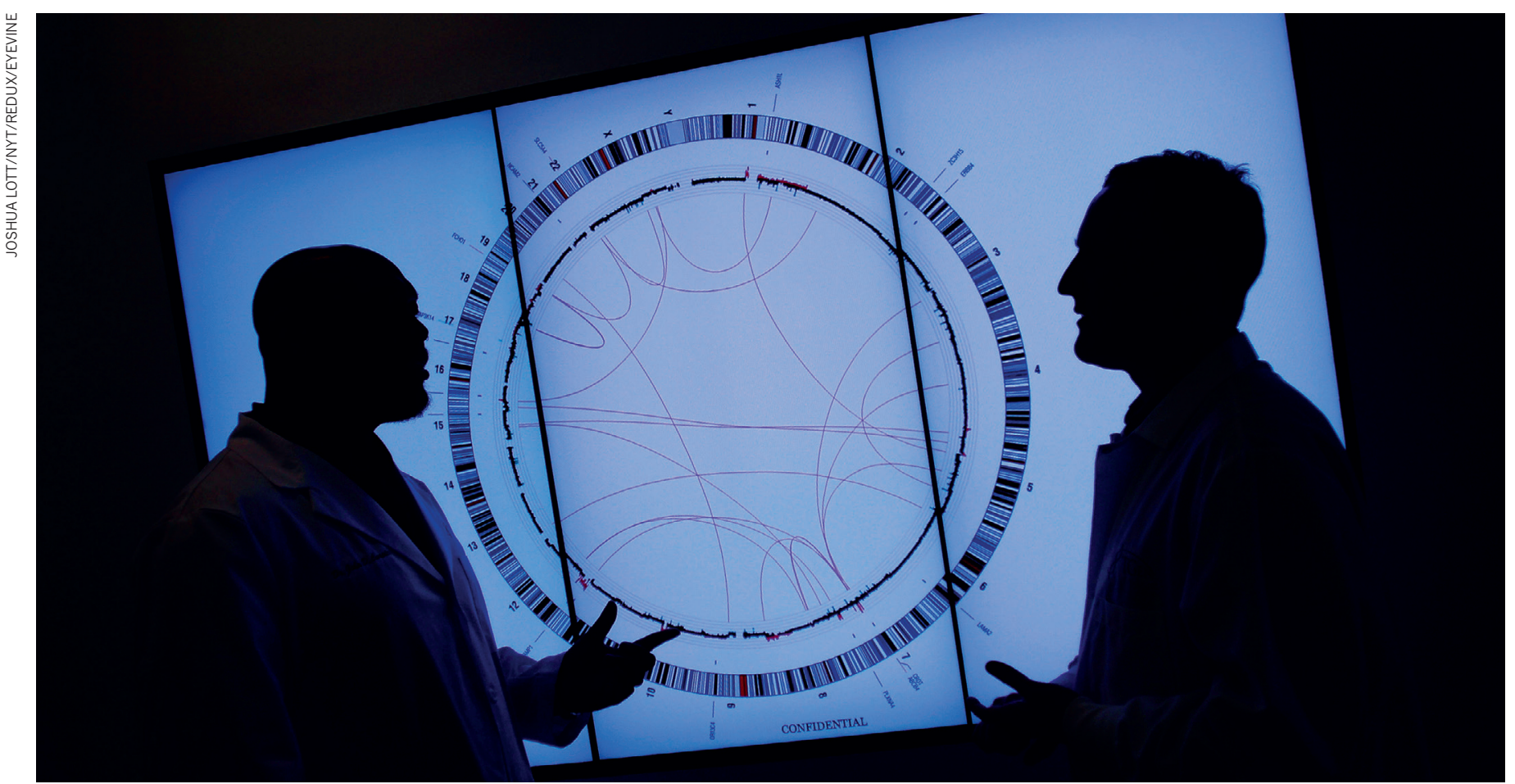

Two researchers in front of a display showing the DNA sequence of a patient's cancer cell.

\title{
Rename breast-cancer
}

\section{syndrome to help save lives}

People of all sexes can have risk genes that are often assumed to affect only women. A new name could aid cancer prevention and treatment, argues Colin C. Pritchard.

I recently had a conversation with my parents about genetic testing for cancer risk. "You mean men also have the BRCA genes?" asked my dad. "I thought those were the breast-cancer genes," chimed in my mom.

My parents are far from alone in not realizing that people of all sexes (including transgender people) can have mutations in BRCA1 and BRCA2 genes. These genes do encode the proteins associated with susceptibility to breast cancer. But they are also associated with an increased risk of prostate and pancreatic cancer, among others.

Because this is not widely understood, testing is not being done for the right people at the right time. Those who identify as men are especially less likely to be tested ${ }^{1}$. And people who are tested can have difficulty understanding the full meaning of their results - regarding both their own cancer risk, and the risks to their family members.

In the past year, I was involved in the care of a man with late-stage prostate cancer. He knew that his sister carried a BRCA2 mutation, but he had not been tested for it because none of his medical practitioners had recommended the test. He'd been unable to walk because of cancer-related pain, and was considering hospice care when a new oncologist suggested a genetic test. Finding out that he carried the $B R C A 2$ mutation allowed him to start a more effective cancer treatment, and in weeks he was able to play golf. What's more, the man had two daughters who thought they weren't at risk for the BRCA2 mutation because it was on their father's side. Both were tested and used the results to take preventive measures that substantially reduce their chances of developing breast and ovarian cancer.

In my view, part of the confusion stems from the fact that people with mutations in $B R C A 1$ or $B R C A 2$ are said to have hereditary breast and ovarian cancer syndrome, or HBOC. This term is not 
only misleading, it is also cumbersome and hard to remember. Fortunately, there is a simple solution: rename the syndrome.

\section{WHAT'S IN A NAME?}

Depending on the population, between 1 in $B R C A 1$ or $B R C A 2$. As such, I estimate that this confusion could be affecting thousands of people with cancer, and their families.

All sexes have the same rate of $B R C A 1$ or $B R C A 2$ mutation; all are equally likely to pass these mutations to their children. Yet a study last year found that, in the United States, over ten times more women were tested for these mutations than were men ${ }^{1}$ (see 'Missed tests'); rates of testing for genes associated with colon-cancer risk were equal. Other studies have shown that men who have been tested for BRCA1 or BRCA2 mutations and diagnosed with $\mathrm{HBOC}$ are often uncertain about their risks of developing cancer, and sometimes keep the information from their families for fear of stigmatization ${ }^{2,3}$.

As is the case for many terms in medicine, the precise origin of 'HBOC' is difficult to pin down. It first appeared in the scientific literature in the early 1990s, around the time when the $B R C A 1$ gene was identified. In previous decades, people had described hereditary breast cancer and hereditary ovarian cancer as distinct entities, on the basis that such cancers cluster in families. The discovery of BRCA1, and then of $B R C A 2$, allowed clinicians to link $\mathrm{HBOC}$ with a specific genetic cause. But at that time, the full spectrum of cancers associated with these two genes was not known.

I propose that HBOC be renamed King syndrome. This is easy to remember. It doesn't imply that the condition affects only one sex, or that people with $B R C A 1$ or $B R C A 2$ mutations will develop only certain types of cancer. And it would recognize the seminal contributions of pioneering cancer geneticist Mary-Claire King, the discoverer of $B R C A 1$ (see 'Cancer-genetics pioneer').

\section{INSTANT IMPACT}

Changing HBOC to King syndrome could have immediate benefits - for health-care providers and for all patients.

Flexibility. Removing the sex and cancer specificity from the name would allow more flexibility as scientific knowledge evolves.

People with mutations in genes other than $B R C A 1$ and $B R C A 2$ can have a syndrome that is similar to HBOC. In fact, some investigators have suggested renaming the gene PALB2 as $B R C A 3$. ( $P A L B 2$ encodes a protein that is involved in the same DNA-repair pathway as the BRCA2 protein, and mutations in both have similar effects ${ }^{4}$.) In short, the term King syndrome would enable researchers to link other genes to the syndrome more easily as scientific understanding advances.

Communication. Changing the name would also make it easier for people to 40 and 1 in 400 people carry a mutation in
MISSED TESTS

Over 10 times more women than men reported having been tested for BRCA1 or BRCA2 mutations*, of around 34,000 survey responders in the United States.
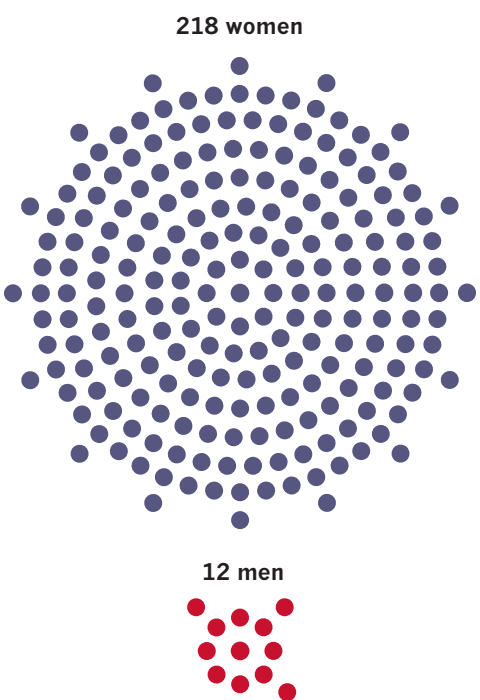

appreciate that the syndrome occurs in all sexes, can be passed through the male lineage, and can be linked to genes that are not specifically named for breast or ovarian cancer.

Take prostate cancer. The latest US clinical guidelines recommend that people with the most advanced form of prostate cancer are tested for BRCA1 and BRCA2 mutations. This stems from the discovery that a high proportion of people with prostate cancer that has spread to other areas (metastatic) carry mutations in these genes, as well as in other related DNA-repair genes conventionally associated with breast and ovarian cancer. The recommendation also arises from the finding that the presence of such mutations has an impact on the effectiveness of treatments ${ }^{5-8}$.

Yet it is only recently that guidelines on prostate cancer were updated to recommend
BRCA1 and BRCA2 testing. Before 2017, health-care providers in the United States would have found recommendations seemingly focused on breast and ovarian cancer. Specifically, the information could be found only in guidelines titled 'Genetic/Familial High-Risk Assessment: Breast and Ovarian'.

\section{IN GOOD COMPANY}

There is precedent for renaming a cancer-risk syndrome after a leading scientist for clarity.

For several years, health-care providers and others referred to people with mutations in any of four genes involved in a certain type of DNA-repair mechanism as having hereditary non-polyposis colorectal cancer syndrome, or HNPCC. But over the past ten years, specialists have returned to the original terminology: Lynch syndrome. (US physician Henry Lynch, who died last month, did much of the pioneering work in the 1960s and 1970s to identify the familial syndrome ${ }^{10}$.)

As with $\mathrm{HBOC}$, clinicians and others found the name HNPCC misleading, because it did not accurately reflect the types of cancer to which it has been linked. People with Lynch syndrome are more likely to get colorectal cancer, but can also develop cancer of the endometrium (which begins in the uterus), stomach and ovaries, as well as some forms of bladder cancer, among many others. These individuals are also at risk of developing precancerous lesions in the colon (colorectal polyps), making the 'non-polyposis' part of the old name especially misleading.

Some might disagree that King syndrome is the best choice for a new name, because it doesn't describe the syndrome. They might instead favour something like 'homologous recombination DNA repair deficiency syndrome'. But such a name would again be hard to remember for providers and patients.

Others might worry that testing rates among cisgender women (whose gender is

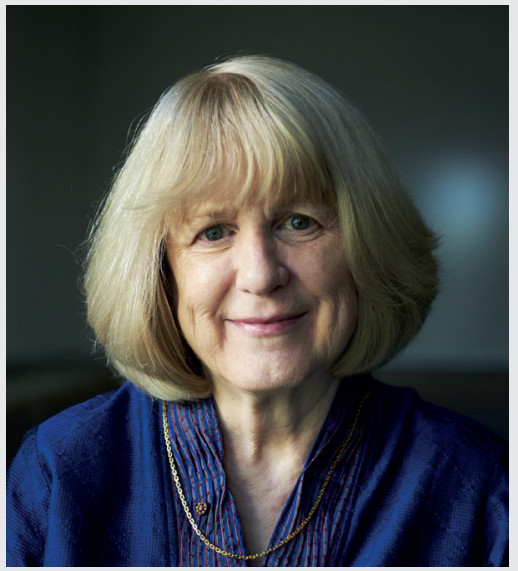

In the mid-1970s, Mary-Claire King (pictured) was the first to recognize that hereditary breast and ovarian cancer could be accounted for by a single gene; in 1990, she and her group at the University of California, Berkeley, identified the location of the BRCA1 gene ${ }^{13,14}$. Now at the University of Washington, Seattle, King is recognized ${ }^{15}$ as a founder of cancer genetics and a long-term advocate for BRCA1 and BRCA2 testing.

Hundreds of thousands of people have been tested for mutations in these genes, and many lives have been saved through cancer prevention. Yet, with an estimated 19 million mutation carriers worldwide at least, we have only scratched the surface. C.C.P. 
of the same as their birth sex) could decrease under the new name (especially given the male connotations of the word 'king'), and that related health care could suffer. I acknowledge the potential downsides, but think that these would be outweighed by improvements in care that could follow. The name could help people to understand that their cancer risk is not limited to breast and ovarian cancer. It might also help them to better communicate the risks to their family members, or to a new health-care provider, and so increase the chance that testing is done.

Renaming HBOC could even spark a wider discussion around confusing names for cancer genetic syndromes. Hereditary diffuse gastric cancer syndrome, for instance, is caused chiefly by inherited mutations in $C D H 1$, which encodes a protein that helps to establish and maintain the shape of epithelial cells, such as those found in the gut lining. People with these mutations are much more likely than the general population to develop a certain type of breast cancer ${ }^{11}$, and the children of families with this syndrome are at risk of having some types of congenital malformation, such as a cleft lip ${ }^{12}$.

Ultimately, using names that are simple and flexible, instead of obtuse and out of step with emerging understanding, could save lives by improving communication and awareness. -

Colin C. Pritchard is associate professor in the Department of Laboratory Medicine, University of Washington, and head of precision diagnostics at the Brotman Baty Institute for Precision Medicine, Seattle, Washington, USA. He is a colleague of Mary-Claire King. e-mail:cpritch@uw.edu

1. Childers, K. K., Maggard-Gibbons, M., Macinko, J. \& Childers, C. P. JAMA Oncol. 4 876-879 (2018).

2. Rauscher, E. A., Dean, M. \& Campbell-Salome, G. M. J. Genet. Couns. 27, 1417-1427 (2018).

3. Strømsvik, N., Råheim, M., Øyen, N., Engebretsen, L. F. \& Gjengedal, E. J. Genet. Couns. 19, 360-370 (2010)

4. Antoniou, A. C. et al. N. Engl. J. Med. 371, 497-506 (2014).

5. Castro, E. et al. J. Clin. Oncol. 31, 1748-1757 (2013).

6. Mateo, J. et al. N. Engl. J. Med. 373, 16971708 (2015).

7. Na, R. et al. Eur. Urol. 71, 740-747 (2017).

8. Pritchard, C. C. et al. N. Engl. J. Med. 375, 443-453 (2016)

9. National Comprehensive Cancer Network. Genetic/Familial High-Risk Assessment: Breast and Ovarian Version 2.2019 (2019).

10.Lynch, H. T., Snyder, C. L., Shaw, T. G., Heinen, C. D. \& Hitchins, M. P. Nature Rev. Cancer 15, 181-194 (2015).

11. Hansford, S. et al. JAMA Oncol. 1, 23-32 (2015).

12.Figueiredo, J. et al. J. Med. Genet. 56 199-208 (2019).

13. Hall, J. M. et al. Science 250, 1684-1689 (1990).

14.King, M. C. Science 343, 1462-1465 (2014).

15.King, M. C., Levy-Lahad, E. \& Lahad, A. J. Am. Med. Assoc. 312, 1091-1092 (2014).

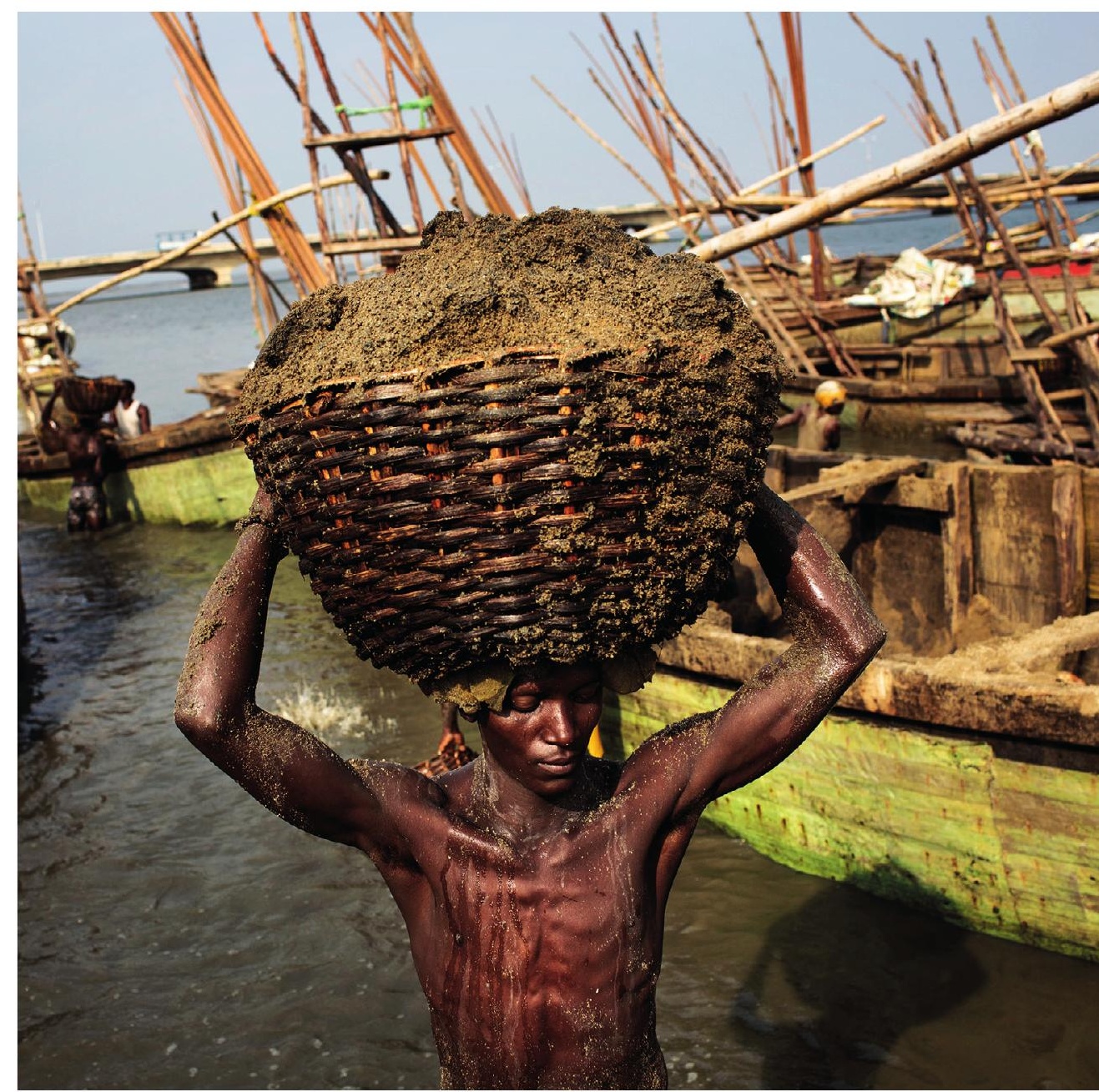

In Lagos Lagoon in Nigeria, labourers dig sand from the sea floor by hand.

\section{Time is running out for sand}

$\mathrm{W}$ hat links the building you live in, the glass you drink from and the computer you work on? Sand. It is a key ingredient of modern life and yet, astonishingly, no-one knows how much sand there is or how much is being mined.

Sand and gravel make up the most extracted group of materials, even exceeding fossil fuels ${ }^{1}$. Urbanization and global population growth are fuelling an explosion in demand, especially in China, India and Africa ${ }^{2}$. Roughly 32 billion to 50 billion tonnes are used globally each year, mainly for making concrete, glass and electronics ${ }^{3}$.
This exceeds the pace of natural renewal ${ }^{4}$ such that by mid-century, demand might outstrip supply ${ }^{2}$ (see 'Global scarcity'). A lack of knowledge and oversight is allowing this unsustainable exploitation.

Desert sand grains are too smooth to be useful, and most of the angular sand that is suitable for industry comes from rivers (less than $1 \%$ of the world's land $)^{5}$. This extraction of sand and gravel has far-reaching impacts on ecology, infrastructure and the livelihoods of the 3 billion people who live along rivers $3,6,7$ (see 'Shifting sands'). For example, sand mining on the Pearl River (Zhujiang) in China 